\title{
Human growth hormone and human prolactin function as autocrine/paracrine promoters of progression of hepatocellular carcinoma
}

\author{
Xiangjun Kong ${ }^{1,2, *}$, Wenyong Wu $\mathbf{u}^{3, *}$, Yan Yuan ${ }^{1,2}$, Vijay Pandey ${ }^{4}$, Zhengsheng $\mathbf{W u}^{5}$, \\ Xuefei Lu ${ }^{1,2}$, Weijie Zhang ${ }^{1,2}$, Yijun Chen ${ }^{4}$, Mingming Wu ${ }^{1,2}$, Min Zhang ${ }^{1,2}$, Gaopeng $\mathrm{Li}^{1,2}$, \\ Sheng Tan ${ }^{1,2}$, Pengxu Qian ${ }^{1,2}$, Jo K. Perry6, Peter E. Lobie ${ }^{4,7}$, Tao Zhu ${ }^{1,2}$ \\ ${ }^{1}$ The CAS Key Laboratory of Innate Immunity and Chronic Disease, School of Life Sciences and Medical Center, University of \\ Science and Technology of China, Hefei, Anhui, China \\ ${ }^{2}$ Hefei National Laboratory for Physical Sciences at Microscale, Hefei, Anhui, China \\ ${ }^{3}$ Department of General Surgery, First Affiliated Hospital of Anhui Medical University, Hefei, Anhui, China \\ ${ }^{4}$ Cancer Science Institute of Singapore and Department of Pharmacology, National University of Singapore, Singapore \\ ${ }^{5}$ Department of Pathology, Anhui Medical University, Hefei, Anhui, China \\ ${ }^{6}$ Liggins Institute, University of Auckland, Auckland, New Zealand \\ ${ }^{7}$ National University Cancer Institute of Singapore, National University Health System, Singapore \\ *These authors have contributed equally to this work \\ Correspondence to: Tao Zhu, e-mail: zhut@ustc.edu.cn \\ Peter E. Lobie, e-mail: csipel@nus.edu.sg
}

Keywords: growth hormone, prolactin, hepatocellular carcinoma, oncogenicity, survival

Received: May 19, 2015

Accepted: March 24, 2016

Published: April 18, 2016

\section{ABSTRACT}

The death rates of hepatocellular carcinoma (HCC) are extremely high due to the paucity of therapeutic options. Animal models and anecdotal clinical evidence indicate a potential role of hGH and hPRL in HCC. However, the prognostic relevance and the functional role of tumor expression of these hormones in human HCC are not defined. Herein, we analyzed the mRNA and protein expression of hGH and hPRL in histopathological samples of non-neoplastic liver and HCC by in situ hybridization, PCR and immunohistochemistry techniques. Increased mRNA and protein expression of both hormones was observed in HCC compared with non-neoplastic liver tissues. hGH expression was significantly associated with tumor size and tumor grade. No significant association was observed between the expression of hPRL and any histopathological features. Amplification of both hGH and hPRL genes in HCC was observed when compared to non-neoplastic tissue. Expression of both hGH and hPRL was associated with worse relapse-free and overall survival in HCC patients. In vitro and in vivo functional assays performed with HCC cell lines demonstrated that autocrine expression of hGH or hPRL in HCC cells increased STAT3 activation, oncogenicity and tumor growth while functional antagonism with hGH-G120R significantly reduced these parameters. Hence, tumor expression of hGH/hPRL is associated with a worse survival outcome for patients with HCC and hGH/hPRL function as autocrine/paracrine promoters of HCC progression.

\section{INTRODUCTION}

In addition to their classic endocrine actions, human growth hormone (hGH) and human prolactin (hPRL) have been reported to function as autocrine and/or paracrine growth factors in tissues such as the mammary gland, endometrium, prostate and central nervous system including the retina [1]. Previous studies have also demonstrated that autocrine expression of hGH and hPRL promoted oncogenicity and progression of carcinomas derived from a range of tissues [2-6] and autocrine $\mathrm{hGH}$ may serve as a transforming oncogene at least for 
mammary epithelial cells [7]. Furthermore, independent of serum hGH, hPRL or IGF1 levels, expression of hGH or hPRL in mammary or endometrial carcinoma is associated with unfavorable histopathological features with a significantly worse survival outcome for patients [8]. Thus, both hGH and hPRL exert tissue and disease specific functions in an autocrine/paracrine manner.

Both the GH receptor and PRL receptor were first identified and characterized in liver $[9,10]$. Indeed, the liver has been considered a predominant target organ for both GH and PRL [11]. In the human, hGH activates both the hGH receptor and the hPRL receptor [12]. The majority of GH dependent serum IGF1 is hepatic derived [13] and patients with hepatic cirrhosis exhibit decreased serum IGF1 with concomitant elevated GH [14] indicative of $\mathrm{hGH}$ resistance. Aberrations in the somatotropic axis have previously been implicated in the development of HCC. For example, mice transgenic for GH spontaneously develop HCC [15] and display enhanced carcinogen induced HCC [16]. In contrast, GH deficient mice are dramatically resistant to the development of carcinogen induced liver cancer [17]. Furthermore, hGH administration promotes growth of hGHR positive human hepatocellular and gastric carcinoma cell lines $[18,19]$. Similar to GH, PRL has been reported to function as a tumor promoter for chemically initiated rat liver cells [20]. Recently, several investigations identified that serum PRL levels were significant elevated in HCC patients and PRL was one of the potential tumor markers for HCC, suggesting that hPRL may be useful as a biomarker for early detection of $\mathrm{HCC}$ and may play a role in HCC progression [21-23].

Although increased cellular expression of both the hGHR and hPRLR has been observed in HCC [24] and increased serum hGH and hPRL levels have been observed in $\mathrm{HCC}$ patients $[25,26]$, the potential tumor expression of hGH and hPRL, clinicopathological associations and prognostic significance remain unknown. Herein, we report the expression of hGH and hPRL in HCC, an association of hGH and hPRL expression with poor survival outcome and provide detailed in vitro and in vivo functional analyses which support an autocrine and/or paracrine role for both $\mathrm{hGH}$ and hPRL in human HCC progression.

\section{RESULTS}

\section{Expression of hGH and hPRL in hepatocellular carcinoma and adjacent non-tumor tissue}

We utilized ISH to detect hGH or hPRL mRNA in HCC specimens (Figure 1A). Increased expression of both hGH and hPRL mRNA was observed in HCC specimens when compared with the corresponding adjacent nonneoplastic hepatic tissue (Supplementary Table S1).

We also determined the mRNA levels of $\mathrm{hGH}$ or hPRL in paired non-neoplastic hepatic tissue and HCC by qPCR. Concordant with the ISH results, eight of twelve patients showed increased expression of hGH mRNA in tumors compared to non-neoplastic hepatic tissue (Figure 1B). The mRNA levels of hPRL exhibited a similar pattern, nine of twelve patients showed increased expression of hPRL mRNA in tumor compared to nonneoplastic hepatic tissue (Figure 1C). We next determined if the genomic loci of hGH and hPRL were amplified in HCC. We therefore performed qPCR on genomic DNA extracted from HCC and adjacent non-neoplastic tissue. Five of twelve patients showed hGH genomic gain $(>1.5$ fold increase) and six of twelve patients showed hPRL genomic gain in tumors (Figure 1D,E). Consistent with our results, the Cancer Genome Atlas project (TCGA) via cBioPortal $[27,28]$ reported in 206 samples, that $18(9 \%)$ and $13(6 \%)$ tumor samples harbored genomic amplification or mRNA upregulation for hGH or hPRL, respectively.

$\mathrm{hGH}$ and hPRL protein expression in the carcinoma and adjacent non-neoplastic tissue from HCC patients exhibited similar (Figure 1A) but not identical patterns as compared to the respective mRNAs. As previously observed in mammary and endometrial tissues [8], such discrepancies may result from the differential sensitivity of ISH vs. IHC. Furthermore, hGH and hPRL are secretory proteins, which may alter cellular retention and/or localization. As shown in Supplementary Table $\mathrm{S} 1$, increased expression of $\mathrm{hGH}$ protein was detected in HCC tissues compared with non-tumorous hepatic tissue. Similarly, the expression of hPRL protein was strongly and significantly increased in HCC compared to that in non-tumorous tissue $(48.3 \%$ and $7.8 \%)$. hPRL protein expression in the non-neoplastic liver tissue was similar but not identical to that observed with the mRNA (Supplementary Table S1).

\section{Correlation between expression of hGH and hPRL, clinicopathological features of HCC and patient survival}

As observed in Supplementary Table S2, high expression of hGH mRNA was positively associated with larger tumor size and higher histological grade. However, no significant association was observed between the high expression of $\mathrm{hPRL}$ protein and any clinicopathological features of $\mathrm{HCC}$ patients. Interestingly, a significant association between the tumor expression of $\mathrm{hGH}$ protein or hPRL mRNA and gender was observed.

To determine whether hGH or hPRL expression in HCC is associated with RFS and OS, we performed Kaplan-Meier analyses on the cohort of patients with HCC. Patients whose tumors expressed low levels of hGH mRNA exhibited a mean 5 year RFS and OS rate of $31.3 \%$ and $28.1 \%$ respectively. In contrast, patients with tumors expressing a high level of hGH mRNA exhibited a mean 5 year RFS and OS rate of $8.8 \%$ and $5.9 \%$ respectively (Table 1 ). No significant correlation 
A
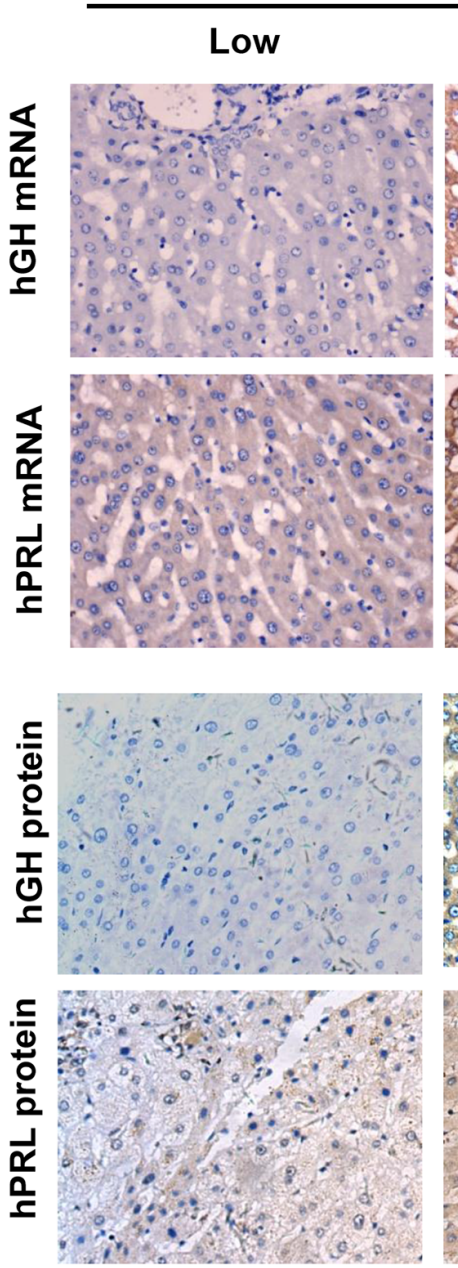

B
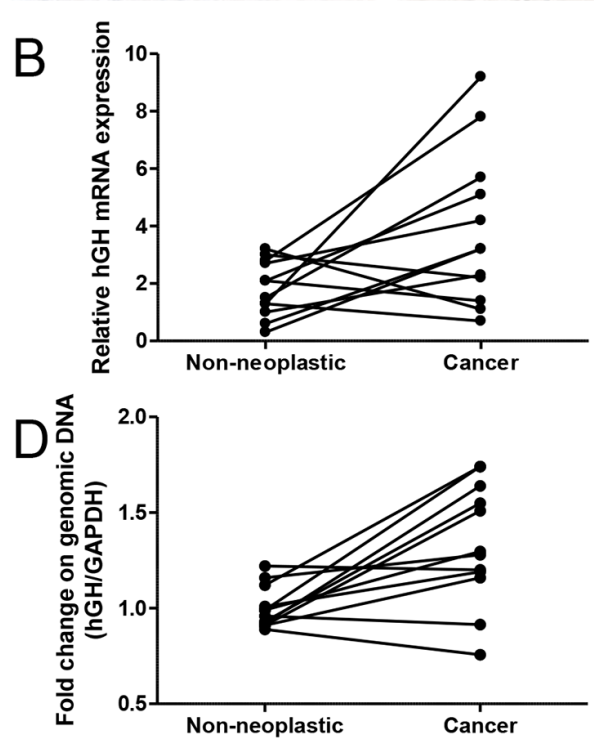

Hepatocelluar carcinoma
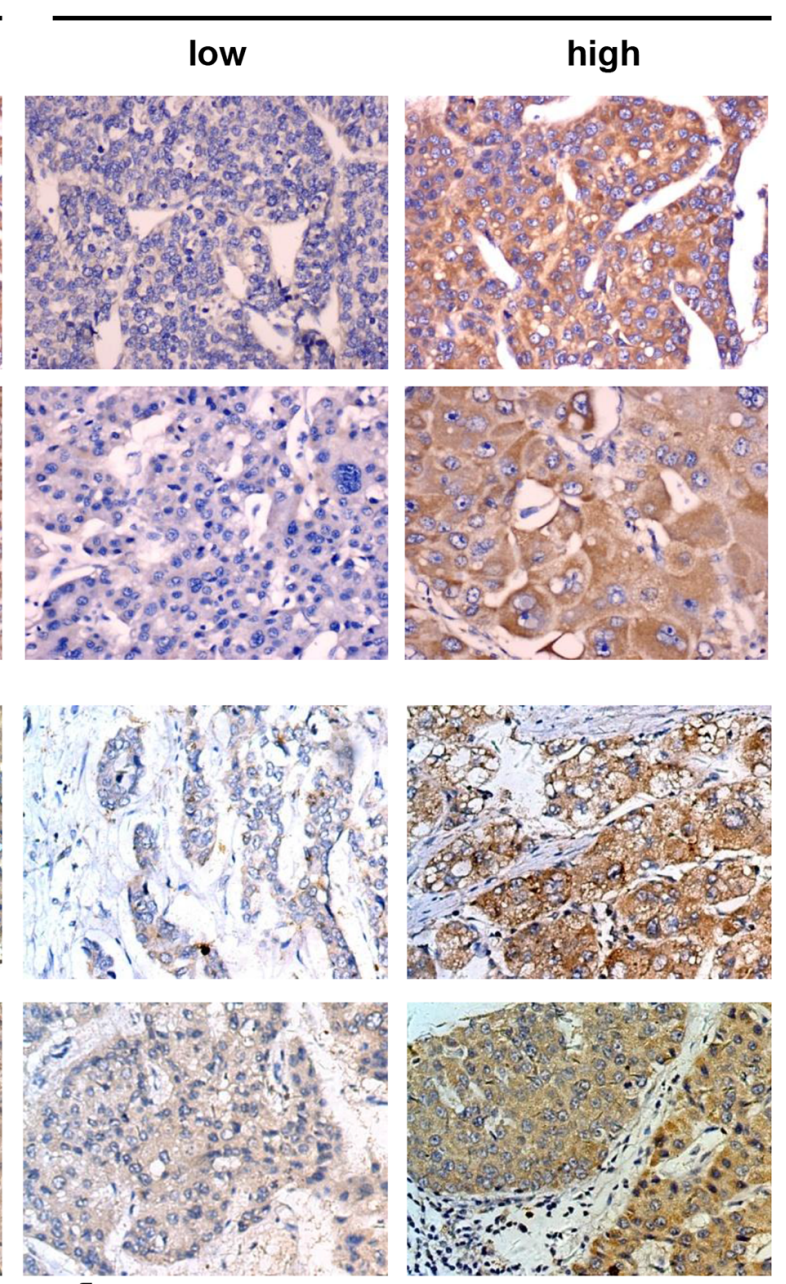

C

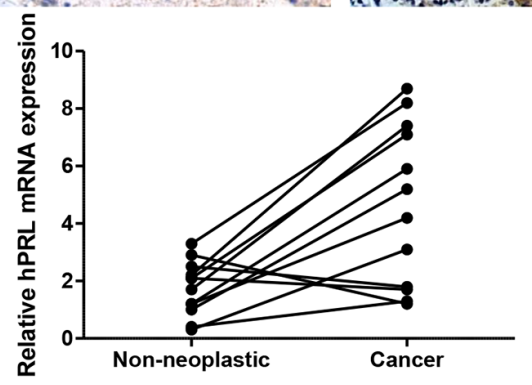

$\mathrm{E}$

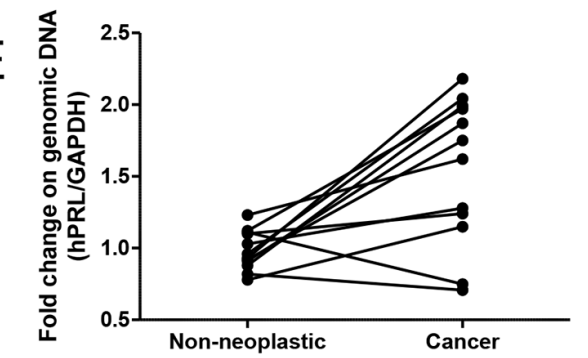

Figure 1: hGH or hPRL expression in hepatic non-neoplastic tissue and hepatocellular carcinoma. A. ISH and IHC analysis of hGH and hPRL expression in non-neoplastic hepatic tissue and HCC. Left two panels, Expression of hGH and hPRL (mRNA and protein) in non-neoplastic hepatic tissue. Right two panels, Expression of hGH and hPRL (mRNA and protein) in HCC. Micrographs were captured at $\times 200$ magnification. B. hGH mRNA levels in HCC and adjacent non-neoplastic tissues detected by qPCR. C. hPRL mRNA levels in HCC and adjacent non-neoplastic tissues detected by qPCR. qPCR on genomic DNA to detect hGH- D. and PRL- E. amplification in HCC and adjacent non-neoplastic tissues. 
Table 1: Association of tumor hGH or hPRL mRNA and hGH or hPRL protein expression with five year relapse free (RFS) and overall survival (OS) in patients with hepatocellular carcinoma

\begin{tabular}{|c|c|c|c|c|c|c|c|c|}
\hline & \multicolumn{8}{|c|}{ Hepatocellular carcinoma } \\
\hline & \multicolumn{4}{|c|}{ RFS (\%) } & \multicolumn{4}{|c|}{ OS (\%) } \\
\hline & mRNA & $\boldsymbol{P}$ & protein & $P$ & mRNA & $P$ & protein & $P$ \\
\hline hGH low/hGH high & $31.3 / 8.8$ & 0.015 & $22.0 / 11.9$ & 0.191 & $28.1 / 5.9$ & 0.026 & $17.1 / 10.2$ & 0.286 \\
\hline hPRLlow/hPRL high & 20.0/10.6 & 0.096 & $25.5 / 6.0$ & 0.009 & $16.1 / 8.5$ & 0.044 & $21.3 / 4.0$ & 0.016 \\
\hline $\begin{array}{l}\text { hGH low hPRL low / } \\
\text { hGH high }\end{array}$ & $31.6 / 7.6$ & 0.035 & $28.0 / 10.7$ & 0.122 & $31.6 / 4.5$ & 0.017 & 20.0/8.9 & 0.254 \\
\hline $\begin{array}{l}\text { hGH low hPRL low / } \\
\text { hPRL high }\end{array}$ & $31.6 / 10.6$ & 0.067 & $28.0 / 6.0$ & 0.037 & $31.6 / 8.5$ & 0.024 & $20.0 / 4.0$ & 0.111 \\
\hline $\begin{array}{l}\text { hGH low hPRL low/ } \\
\text { hGH high hPRL high }\end{array}$ & $31.6 / 2.8$ & 0.011 & $28.0 / 2.9$ & 0.012 & $31.6 / 2.8$ & 0.007 & $20.0 / 0$ & 0.032 \\
\hline
\end{tabular}

was observed between the expression of hGH protein and patient RFS or OS rate. Similarly, patients whose tumors express high levels of hPRL mRNA exhibited a significantly lower OS rate (but not RFS rate), compared to patients whose tumor exhibited low expression of hPRL mRNA. Moreover, patients whose tumors express a high level of hPRL protein exhibited a significantly lower RFS and OS compared to patients whose tumors expressed low levels of hPRL protein respectively. The RFS and OS of patients whose tumors exhibited low expression of both $\mathrm{hGH}$ and hPRL, either mRNA or protein, was higher than patients whose tumors exhibited high expression of either hGH or hPRL (Table 1, Figure 2A, 2B). Furthermore, the RFS and OS rates for patients whose tumors exhibited low expression of mRNA or protein for both hormones were significantly higher when compared to patients whose tumors were high expressing for both hGH and hPRL mRNA or protein expression.

Multivariate analyses also revealed that the adjusted odds ratios for death or relapse of patients with $\mathrm{HCC}$ were significantly increased in patients whose tumors expressed high levels of hGH or hPRL. The adjusted odds ratios are presented in Supplementary Table S3. Combined expression of both hGH and hPRL, at either the mRNA or protein level in HCC, was significantly associated with decreased RFS and OS.

We also examined whether a different prognostic significance of hGH and hPRL expression in HCC existed between genders. Interestingly, in the univariate Kaplan-Meier survival analyses, a significant association between the expression of hGH and hPRL and survival was only observed in males (Supplementary Table S4). No significant association was observed between the expression of such hormones and the survival of female patients. Furthermore, those males with the phenotype of hGH-high-hPRL-high exhibited a shorter OS and RFS than patients with any other phenotype of hGH or hPRL expression (Supplementary Figure S1).

\section{Expression of hGH, hPRL, hGHR and hPRLR mRNAs in HCC cell lines}

We next examined hGH or hPRL mRNA expression in a number of HCC cell lines by RT-PCR. As observed in Figure 3A, hGH mRNA was expressed in HepG2, Bel-7404 and a normal immortalized human liver cell line LO2. hPRL mRNA was expressed in LO2 and almost all HCC cell lines except QGY-7703. hGHR and hPRLR mRNA expression patterns were similar and were expressed in all cell lines examined except QGY-7703. ELISA detection of secreted hGH and hPRL protein in cell medium demonstrated that hGH and hPRL levels vary from 0.02 and 0.1 to 1.9 and $2.6 \mathrm{ng} / \mathrm{ml}$ respectively (Figure 3B).

\section{Autocrine expression of hGH or hPRL promote HCC cell proliferation and survival}

To determine whether autocrine expression of hGH or hPRL modulates HCC cell behavior, we stably transfected Bel-7404 and HepG2 cells with plasmids encoding hGH or hPRL cDNA or with the empty plasmid. To inhibit endogenously produced hGH and hPRL, we established another cell line in which cells were transfected with a plasmid that expresses hGHG120R. G120R is a hGH analogue with a single amino acid substitution at position 120 which acts as a dual hGH and hPRL antagonist and antagonizes signaling from both receptors [29].

The forced expression and secretion of $\mathrm{hGH}$, hPRL and G120R in Bel-7404 and HepG2 cells were verified by RT-PCR (Figure 3C and Supplementary Figure S2A), immunoblot (Figure 3D and Supplementary Figure S2B) and ELISA analysis (Figure 3E and Supplementary Figure S2C). Expression was also verified by immunofluorescence in Bel-7404 stable cell lines (Figure 3F). 
Forced expression of hGH or hPRL in Bel-7404 and HepG2 cells increased total cell number (Figure 4A and Supplementary Figure S3A). In contrast, the proliferation rate of both cell lines with forced expression of G120R decreased significantly (Figure 4A and Supplementary Figure S3A). We also utilized siRNAs to deplete both endogenous hGH and hPRL (Figure 4B and Supplementary
Figure S3B). Total cell number assay demonstrated that the proliferation rate of cells with combined transfection of hGH and hPRL siRNAs were significantly decreased compared with control transfected cells (Figure 4C and Supplementary Figure S3C). Autocrine expression of hGH or hPRL also significantly increased Bel-7404 and HepG2 cell entry into S-phase as determined by BrdU

A

hGH and $h P R L$ mRNA
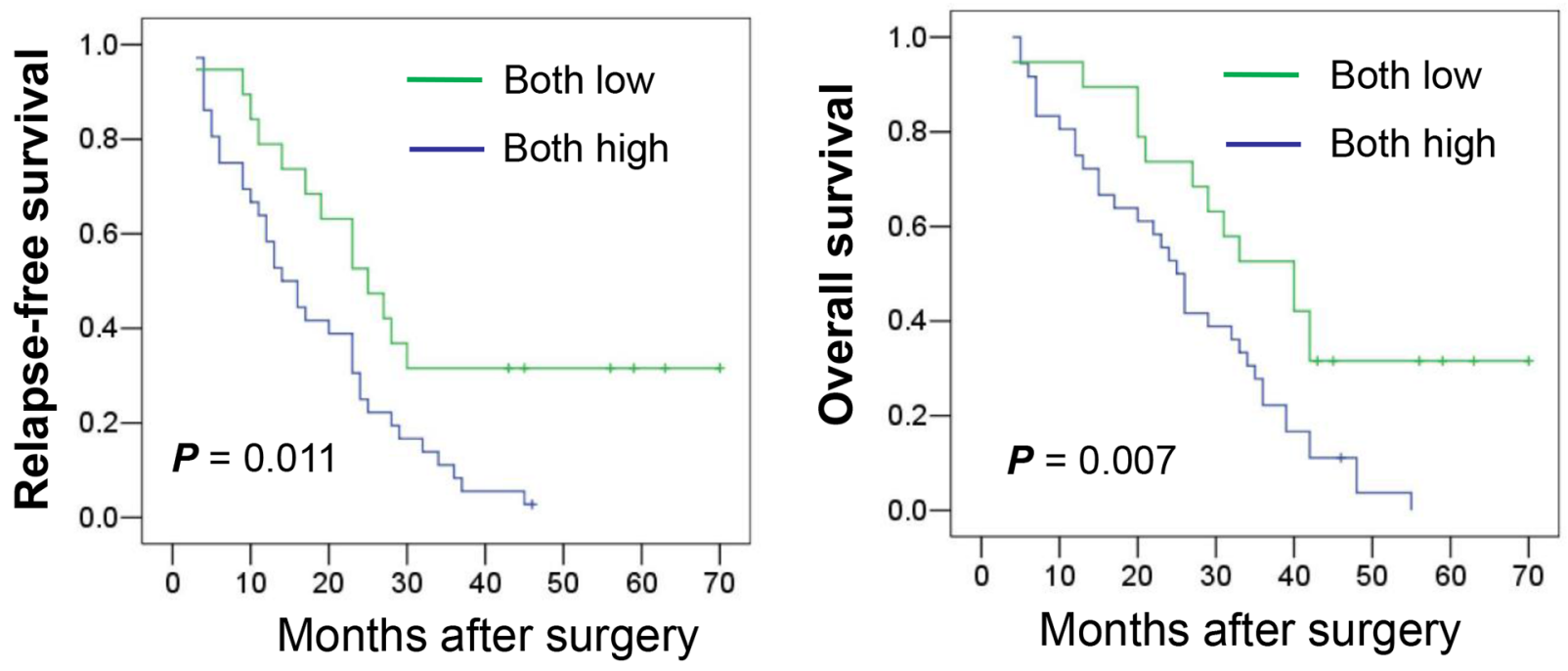

B

$\mathrm{hGH}$ and $\mathrm{hPRL}$ protein
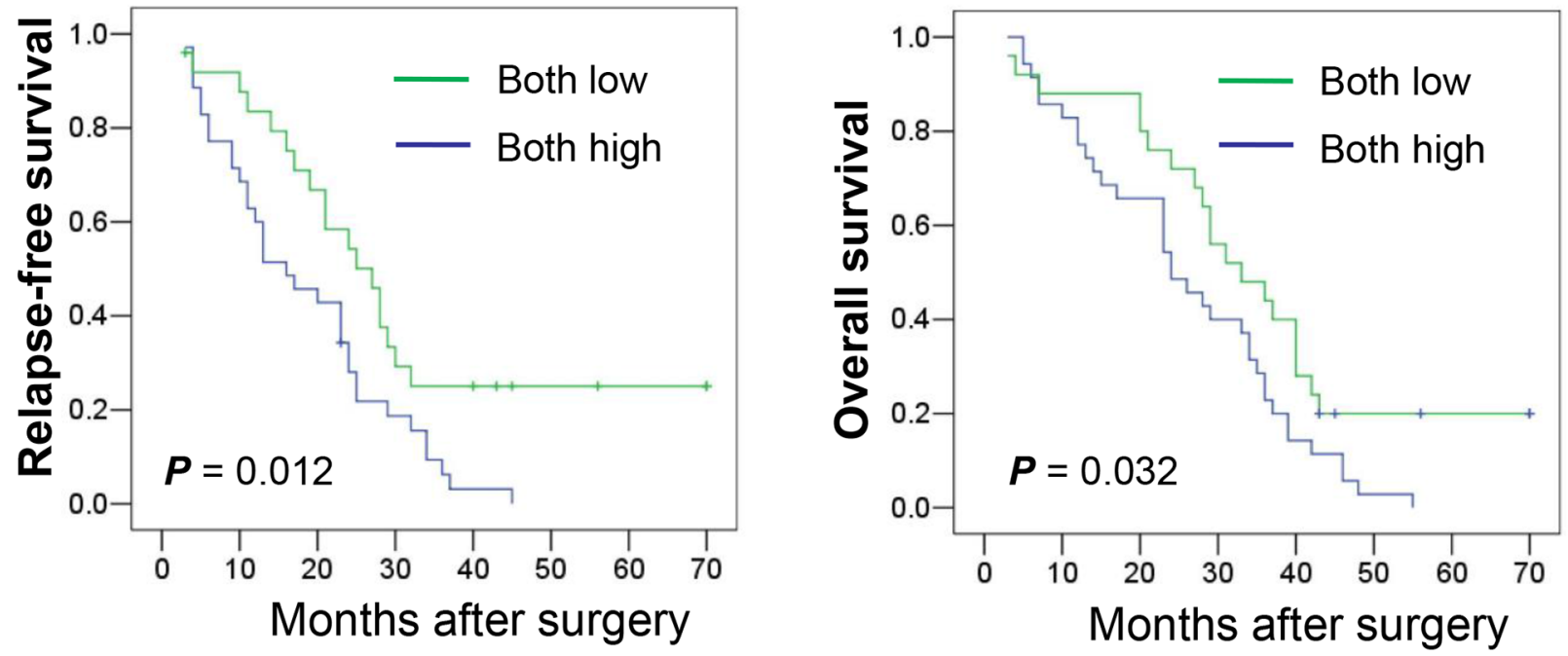

Figure 2: Kaplan-Meier analysis of the significance of hGH and hPRL expression on RFS and OS of patients with HCC. A. The relationship of hGH and hPRL mRNA expression and RFS to OS of patients with HCC. B. The relationship of hGH and hPRL protein expression and RFS to OS of patients with HCC. 


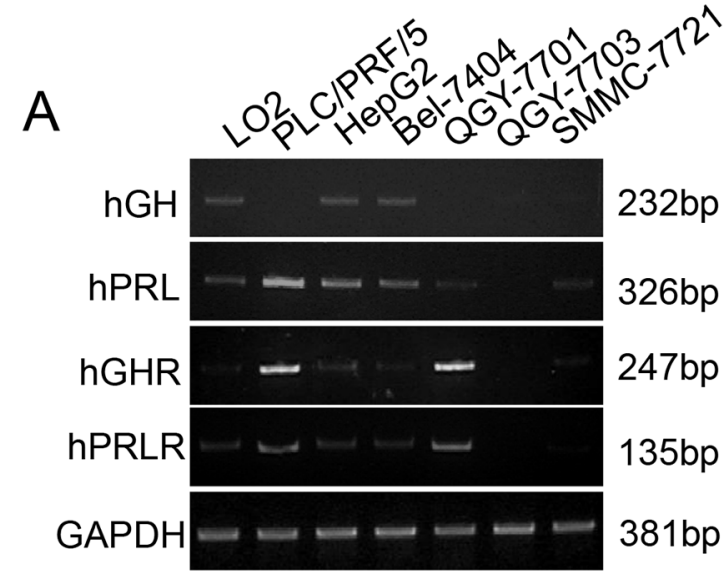

C
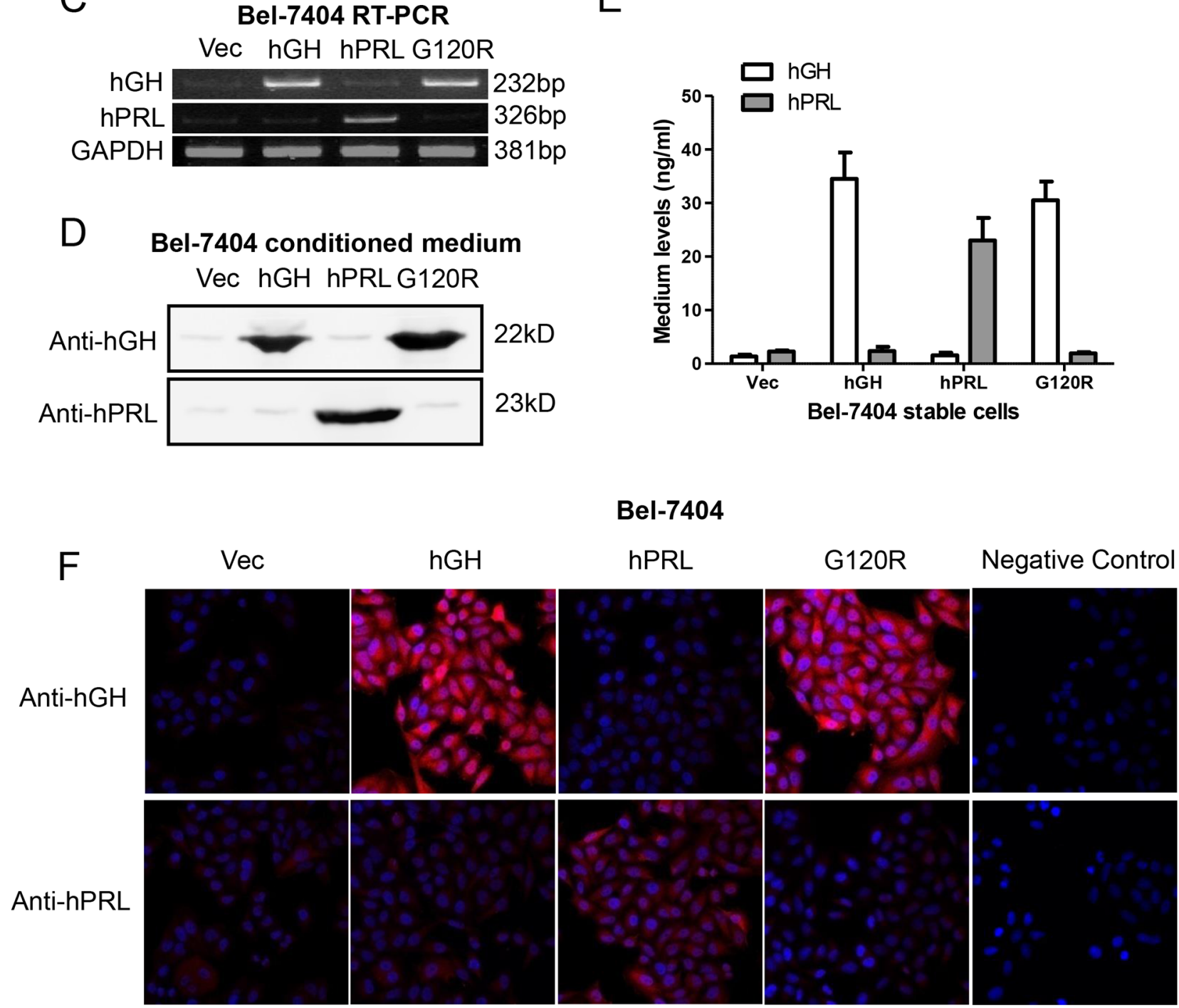

Figure 3: Forced expression of hGH, hPRL and G120R in Bel-7404 cells. A. RT-PCR detection of mRNA expression of hGH, hPRL, hGHR and hPRLR in a panel of cell lines. B. ELISA detection of secreted hGH and hPRL C. RT-PCR analyses of forced expression of hGH, hPRL and G120R in Bel-7404 cells. Immunoblot D. ELISA E. and immunofluorescent F. analyses of forced expression and secretion of hGH, hPRL and G120R in Bel-7404 cells. Mean +/- SD. 

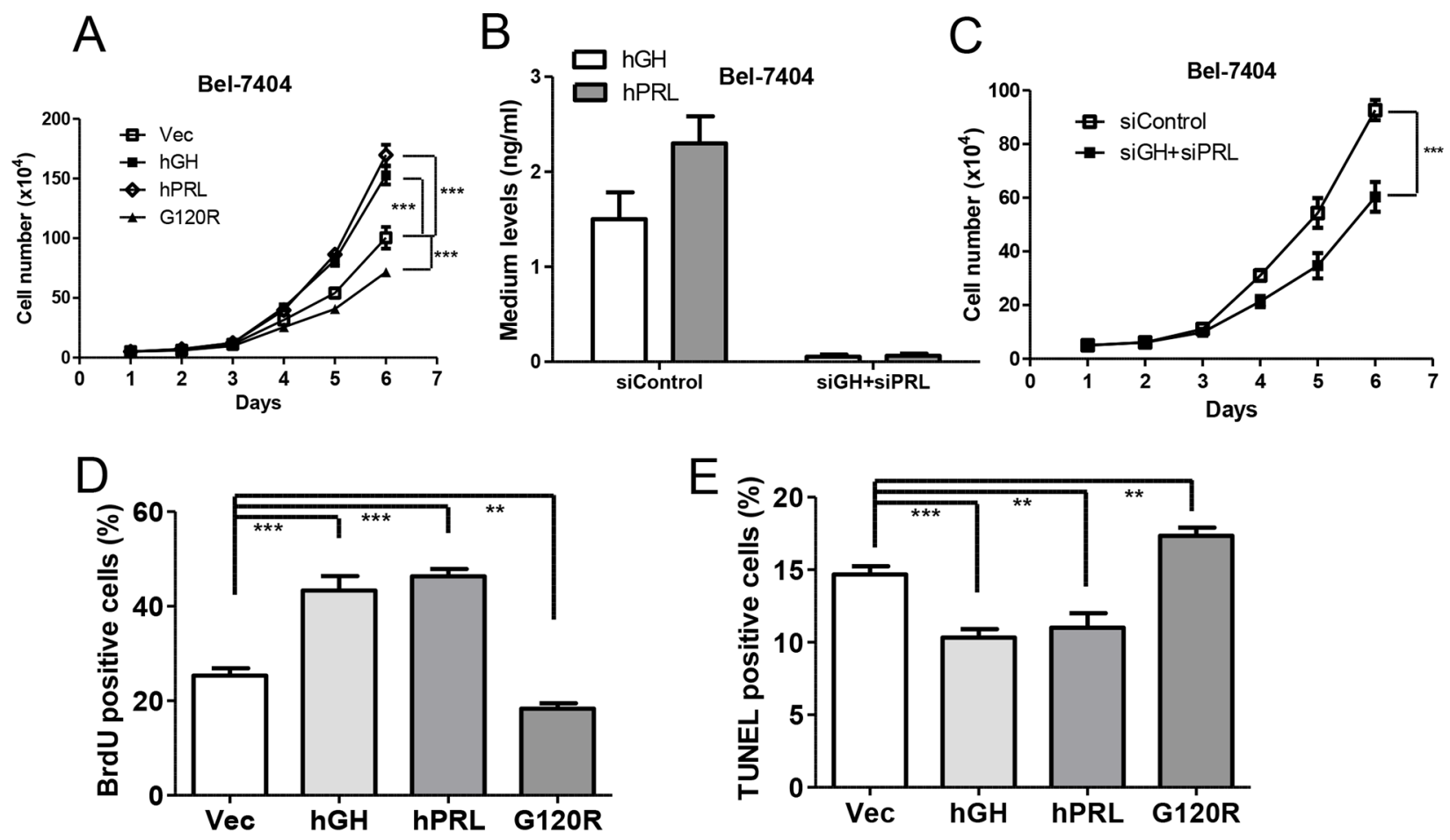

F
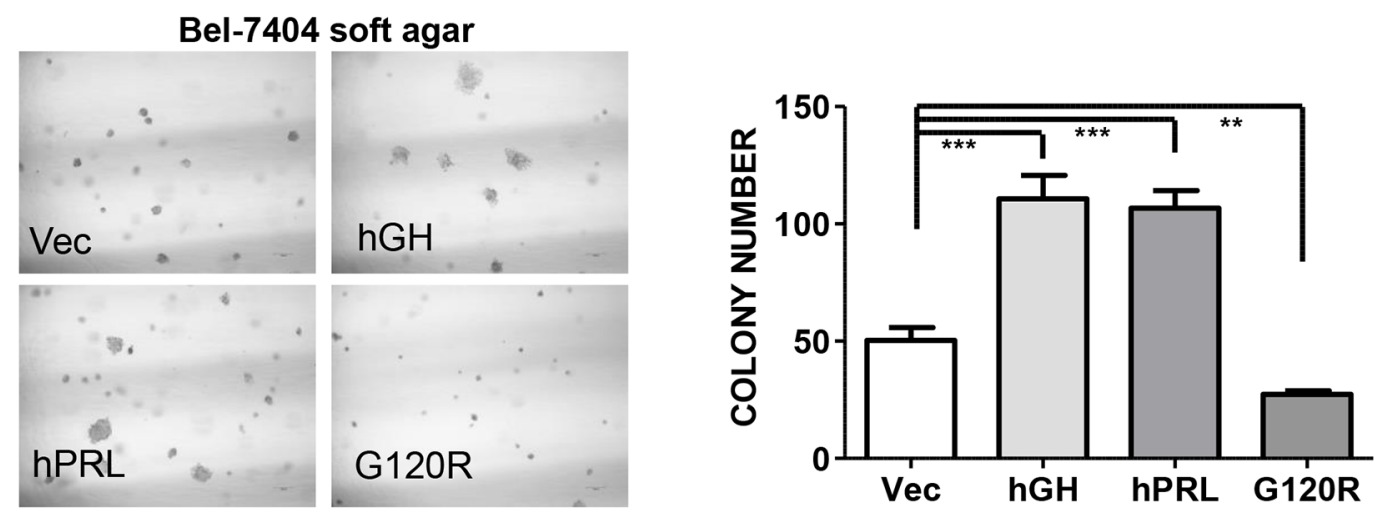

G
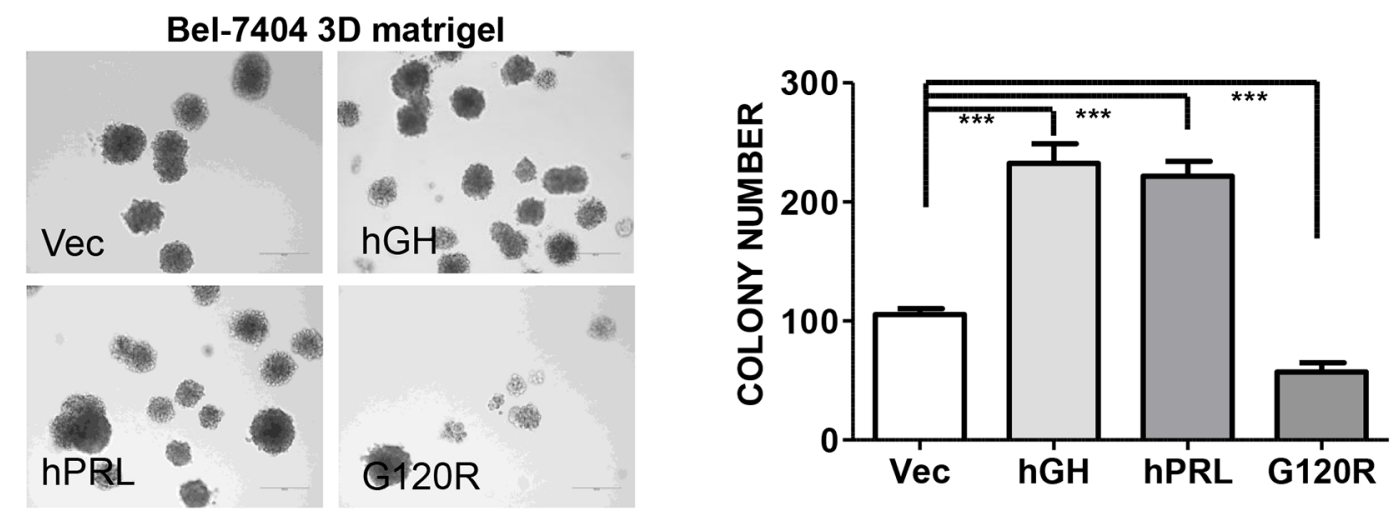

Figure 4: Autocrine expression of hGH or hPRL promote HCC cell oncogenicity in vitro. A. Growth of Bel-7404 cell lines was assessed by a total cell number assay in complete medium. B. ELISA detection of hGH and hPRL levels in medium of Bel-7404 cells with tranfection of control siRNA or combined transfection of hGH and hPRL siRNAs. C. Growth of Bel-7404 cells with combined transfection of hGH and hPRL siRNAs by a total cell number assay in complete medium. Effect of autocrine expression of hGH, PRL or G120R on nuclear BrdU incorporation in complete medium D. on apoptosis induced by serum withdrawal over $48 \mathrm{~h}$ as evaluated by TUNEL assay E. on Soft agar colony formation F. and 3D Matrigel growth G. ** $p<0.01$, *** $\mathrm{p}<0.001$. Mean $+/-$ SD. 
incorporation (Figure 4D and Supplementary Figure S3D). Cell cycle progression was significantly decreased in both cell lines with forced expression of G120R (Figure 4D and Supplementary Figure S3D). Autocrine hGH or hPRL also decreased apoptotic cell death in serum deprived conditions whereas G120R promoted cell apoptosis (Figure 4E and Supplementary Figure S3E). Autocrine hGH or hPRL also significantly increased Bel-7404 and HepG2 cell colony formation in soft agar (Figure 4F and Supplementary Figure $\mathrm{S} 3 \mathrm{~F}$ ) and 3-dimensional growth in Matrigel (Figure 4G and Supplementary Figure S3G) whereas cells with forced expression of G120R formed less colonies.

To further verify the paracrine effects of both hormones, we exposed parental HCC cells to the conditioned medium collected from cells with forced expression of hGH or hPRL. Total cell number assay demonstrated that the proliferation rate of both Bel-7404 and HepG2 cells cultured with the respective conditioned medium from cells with forced expression of hGH or hPRL was significantly increased compared with cells cultured with conditioned medium from the respective vector expressing cells. (Supplementary Figure S4A and S4B).

\section{Autocrine expression of hGH or hPRL modulate gene expression in Bel-7404 cell}

Hepatic production of insulin like growth factors (IGFs) partially mediate the somatic effects of hGH [30]. We therefore ascertained whether autocrine expression of hGH or hPRL modulated IGF1 and IGF2 mRNA levels in Bel-7404 cells by qPCR. Both IGF1 and IGF2 mRNA levels were increased in Bel-7404-hGH cells when compared with control cells (Supplementary Figure S5A, 5B). Surprisingly, autocrine expression of hPRL predominantly promoted IGF1 mRNA expression whereas hGH predominantly stimulated IGF2 mRNA expression (Supplementary Figure S5A, 5B). Both IGF1 and IGF2 mRNA levels were decreased in Bel-7404 cells with forced expression of G120R (Supplementary Figure S5A, B). Furthermore, qRT-PCR analysis on Bel-7404 cell lines demonstrated altered expression of various genes associated with signal transduction, cell cycle progression, cell survival and inflammation by forced expression of hGH or hPRL (Supplementary Table S5). Forced expression of G120R, in general, produced opposing changes in gene regulation to those observed with hGH or hPRL (Supplementary Table S5).

\section{Autocrine expression of hGH or hPRL promote HCC xenograft growth in vivo}

To determine whether autocrine expression of hGH or hPRL enhances HCC growth in vivo, we implanted Bel7404 stable cells subcutaneously in athymic nude mice. Bel-7404 cells with forced expression of hGH or hPRL formed markedly larger tumors and G120R expressing cells produced significantly smaller tumors (Figure 5A). Subsequent quantification of cell proliferation and apoptosis by BrdU or TUNEL labeling on tumor sections demonstrated that hGH or hPRL expressing tumors exhibited higher proliferation and lower apoptosis (Figure 5B, 5C). In contrast, tumors with expression of G120R exhibited less proliferation and higher rates of apoptosis (Figure 5B, 5C).

The levels of human IGF1 protein in mouse serum were observed to be significantly increased in hGH or hPRL expressing tumor bearing mice (Figure 5D). Serum hIGF1 levels of mice bearing tumors with G120R expressing were decreased compared with control mice (Figure 5D).

\section{STAT3 signaling is required for autocrine hGH or hPRL stimulated oncogenicity}

GH has been reported to activate STAT5 in liver [31]. However, in HCC cells with forced expression of hGH or hPRL, we did not observe activation of STAT5 (as determined by phosphorylation of STAT5a/b on Tyr 694/ Tyr 699) (data not shown). As hyperactivation of STAT3 has been postulated to be involved in HCC development [32] and both hGH and hPRL activate STAT3, we next ascertained whether STAT3 signaling was involved in hGH and hPRL stimulation of HCC oncogenicity. Levels of activated STAT3 (pSTAT3-Y705) were observed to be increased by autocrine expression of either hGH or hPRL and decreased by expression of G120R in Bel-7404 cells (Figure 6A). To determine if STAT3 signaling mediates hGH and hPRL stimulated oncogenicity, we depleted STAT3 in Bel-7404 cell lines by shRNA (Figure 6A). Increased colony formation stimulated by either hGH or hPRL in soft agar was significantly abrogated by STAT3 depletion (Figure 6B). Furthermore, treatment of cells with cryptotanshinone, a STAT3 specific inhibitor [33], which efficiently decreased pSTAT3-Y705 levels (Figure 6C), also resulted in inhibition of soft agar colony formation stimulated by autocrine expression of $\mathrm{hGH}$ or hPRL (Figure 6D). In addition, both hGH and hPRL would be expected to activate other signaling pathways in HCC cells and we observed activation of p44/42 MAP kinase (ERK1/2) in both cell lines with forced expression of hGH or hPRL. G120R correspondingly decreased p44/42 MAP kinase levels in HCC cells (Supplementary Figure S6).

\section{DISCUSSION}

This study has demonstrated a significant association of tumor hGH expression with clinicopathological characteristics of HCC. Although we observed no significant association of tumor hPRL expression with any clinicopathological features of $\mathrm{HCC}$, both $\mathrm{hGH}$ and $\mathrm{hPRL}$ expression were individually associated with poor survival of HCC patients overall and specifically 
in male HCC patients. Furthermore, and similar to that observed with both mammary and endometrial carcinoma [8], combined expression of hGH and hPRL predicted a worse survival outcome than that observed with either hormone individually. That tumor expression of hGH and hPRL promotes poor survival outcome in HCC is also consistent with functional assays in which autocrine expression of hGH or hPRL promoted oncogenicity of HCC cells. Again, similar oncogenic effects of autocrine expression of hGH have been demonstrated in mammary [7] and endometrial carcinoma cells [4] and for hPRL in mammary [34], endometrial and ovarian carcinoma cells [35].

IGF1 and IGF2 are expressed in human primary $\mathrm{HCC}$ cells and are involved in HCC development and progression [36]. It has been proposed that many of the effects of hGH on somatic growth are mediated through promotion of hepatic IGF1 synthesis and secretion [37]. Furthermore, IGF2 expression in liver has been reported to be regulated by GH [38]. Concordantly in our models, forced expression of hGH or hPRL increased IGF1 mRNA in Bel-7404 cells in vitro and increased serum hIGF1 in xenograft bearing hosts. In seeming contradiction,
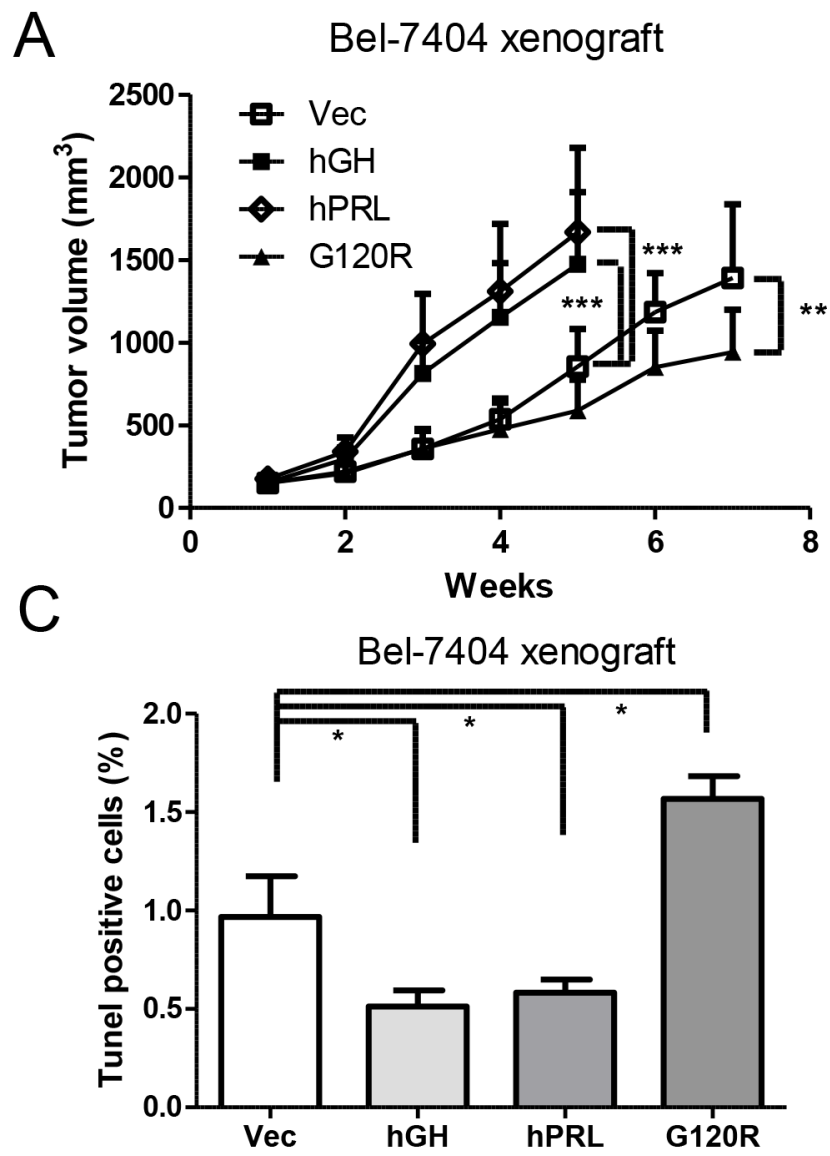

serum IGF1 levels have been reported to be decreased in patients with HCC [39] and the decreased serum IGF1 concentrations in $\mathrm{HCV}$ dependent $\mathrm{HCC}$ is apparently largely independent of liver function [40]. However, tumor expression of IGF1 mRNA in HCC was reported to be significantly increased compared with adjacent non-tumor tissue [41]. In contrast, IGF2 expression is normally suppressed in adult tissues and reactivated in a number of different neoplastic disorders including HCC [42]. hGH and hPRL stimulation of IGF1 or IGF2 in HCC could therefore potentially mediate some of the oncogenic effects of hGH and hPRL. In support of this notion, inhibition of the IGF1R with either antibodies [43] or kinase inhibitor [44] exerts antineoplastic effects in human HCC cell lines. Autocrine produced hGH and hPRL could presumably also exert IGF1 and IGF2 independent oncogenic effects in $\mathrm{HCC}$ as has been previously reported for mammary carcinoma cells [45].

We demonstrated herein that the oncogenic effects of autocrine hGH and hPRL in HCC cells were mediated by STAT3 concordant with the previous report in endometrial carcinoma [46]. Constitutively activated STAT3 is observed in the majority of HCC but not in
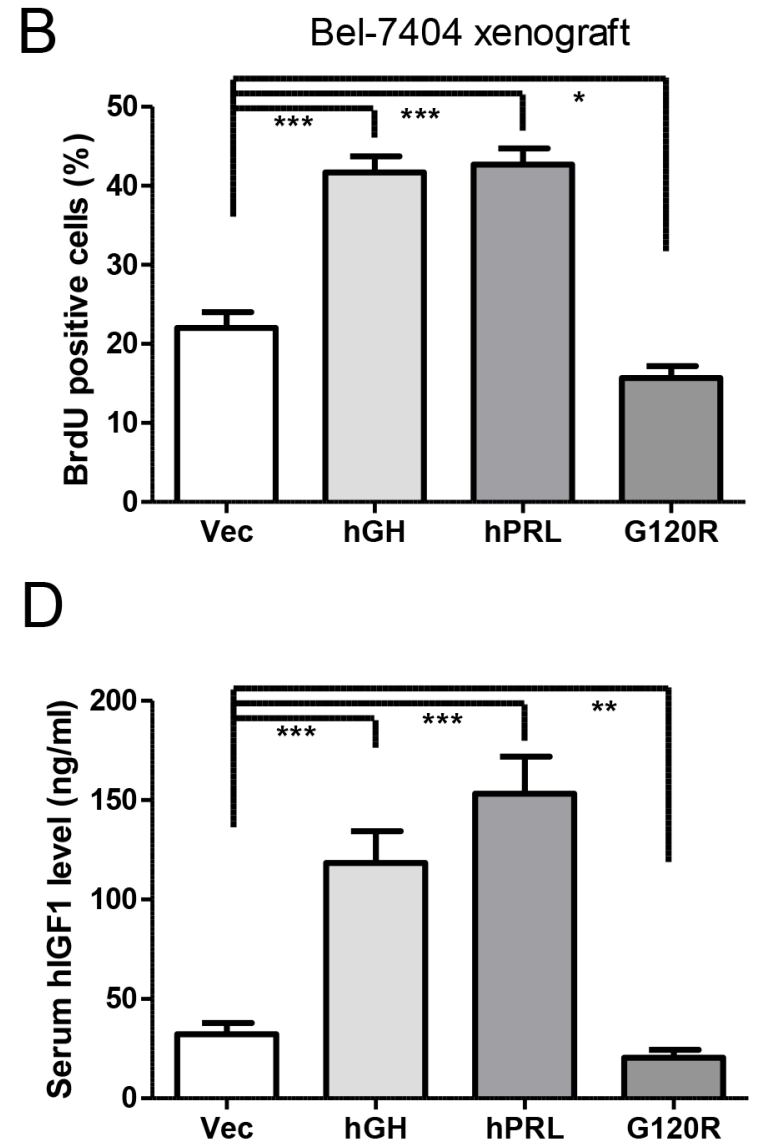

Figure 5: Autocrine expression of hGH or hPRL enhances HCC cell tumor growth in vivo. A. Tumor volume in relation to the day of surgery is shown. B. Evaluation of nuclear BrdU incorporation in tumors. C. Evaluation of TUNEL positive (apoptotic) nuclei in tumors. D. Mouse serum human IGF1 levels were examined by ELISA. ${ }^{*} \mathrm{p}<0.05,{ }^{*} \mathrm{p}<0.01, * * * \mathrm{p}<0.001$. Mean $+/-\mathrm{SD}$. 
normal liver nor adjacent non-tumor tissue [32]. The levels of pSTAT3-Y705 are also associated with histological grade and tumor microvessel density in HCC [32] and larger tumor size, VEGF and Ki67 expression, higher clinical stage and poor patient survival [47]. However, the molecular mechanisms that promote STAT3 activation in HCC are largely unknown. It has been proposed that STAT3 activation in cancer cells is often mediated by cytokines and/or growth factors synthesized within the tumor microenvironment [48]. Experiments herein demonstrated that hGH or hPRL act as tumor produced autocrine or paracrine growth factors that promote the activation of STAT3. Autocrine expression of hGH or hPRL also promoted activation of ERK $1 / 2$ which is a positive regulator of STAT3 (Supplementary Figure S6). Interestingly, autocrine expression of hGH or hPRL also increased the expression of TNF (Supplementary Table S3), a proinflammatory factor involved in STAT3 activation, liver inflammation and tumorigenesis [33], suggesting that STAT3 may be directly or indirectly activated by autocrine expression of hGH or hPRL. We did not observe STAT5 activation in the HCC cell lines with forced expression of hGH or hPRL and hence the effects of hGH and hPRL appear to be independent of STAT5. In this regard it should be noted that GH utilizes STAT5 as an enhancer of IGF-1 gene transcription and there are no STAT5 response elements in the IGF-1 promoter [49]. It should also be noted that STAT3 may promote IGF-1 gene transcription in response to $\mathrm{GH}$ albeit less efficiently than STAT5 [50]. This observation would indeed be consistent with our results herein where the increase in IGF-1 mRNA expression, while significant, is not large.

Recently, a report demonstrating that PRL contributed to the proliferation of liver cancer cells via JAK2 signaling was published [26]. In that report, the serum PRL level was observed to be significantly higher in HCC patients compared to normal controls. It was further reported that PRL promoted JAK2 and STAT3 phosphorylation and Cyclin D1 expression in HepG2 cells [26]. Whilst the organ source of increased PRL in HCC was not identified, this report confirmed our observation of PRL dependent activation of STAT3 in HCC cells [26]. More recently, a controversial study demonstrated that PRL can protect mice from HCC was reported [51]. From their findings, PRL interacted with short form PRLR to constrain tumor promoting liver inflammation. However, as the authors also observed, human HCC cell lines (including the HepG2 cell line used in this study) express
A

Bel-7404

Vec hGH hPRL G120R Vec hGH hPRL G120R
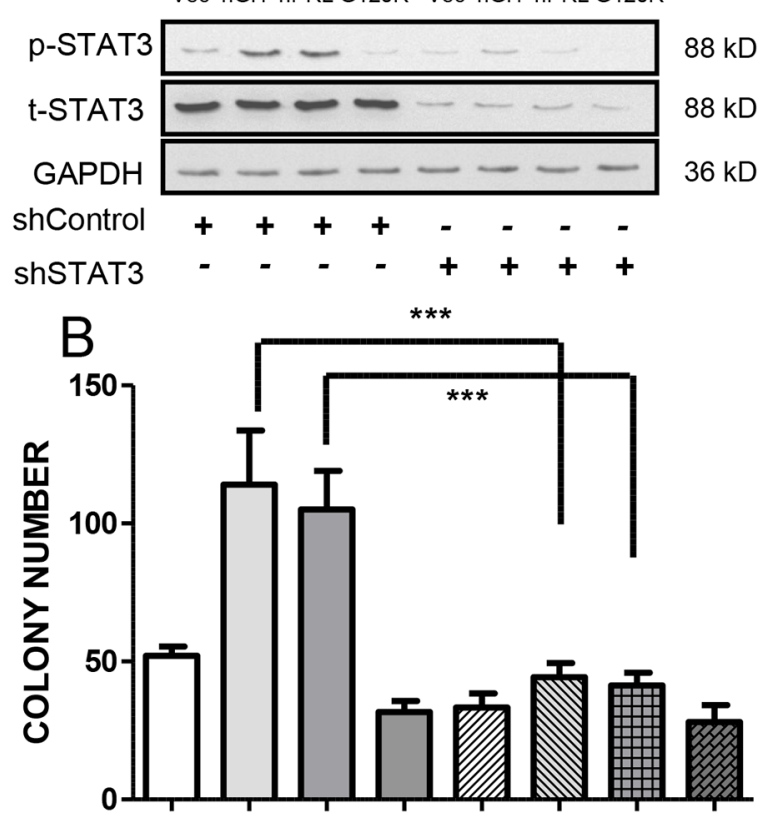

Vec hGH hPRL G120R Vec hGH hPRL G120R
C

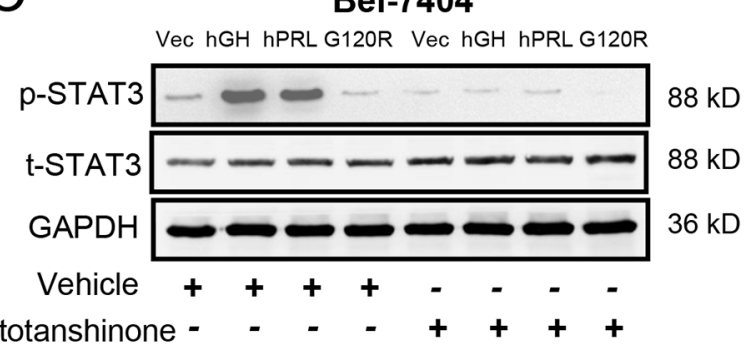

D

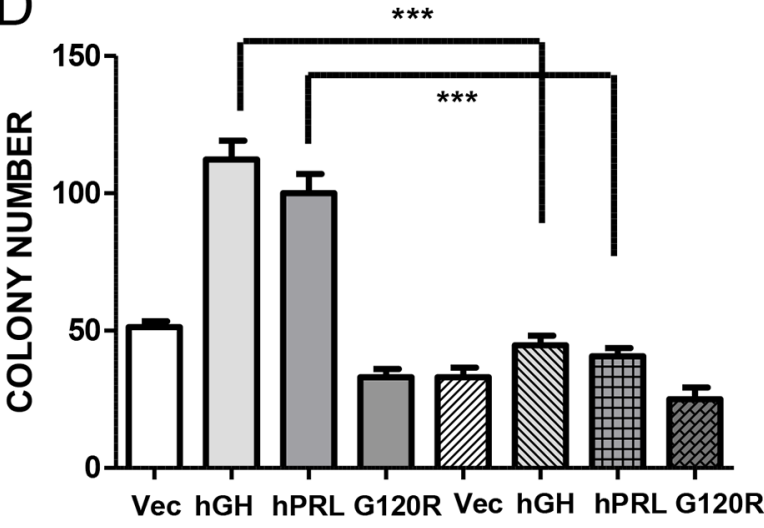

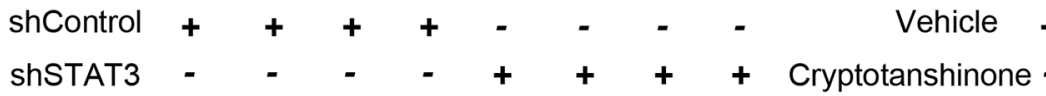

Figure 6: hGH and hPRL stimulated oncogenicity is mediated by STAT3. A. Immunoblot analysis of total STAT3 and pSTAT3 Y705 levels after STAT3 shRNA transfection. B. Soft agar colony formation of Bel-7404 cells transfected with STAT3 shRNA. C. Immunoblot analysis of total STAT3 and pSTAT3-Y705 levels after cryptotanshinone treatment $(10 \mu \mathrm{M})$. D. Soft agar colony formation of Bel-7404 cells treated with cryptotanshinone. ${ }^{*} \mathrm{p}<0.05$, ** $\mathrm{p}<0.01, * * * \mathrm{p}<0.001$. Mean $+/-$ SD. 
the predominant long form of PRLR which activates different pathways compared with the short form PRLR [51]. Therefore, which PRLR isoform is predominant in human $\mathrm{HCC}$ clinical samples requires investigation.

Evidence from experimental models is emerging that functional antagonism of hGH or hPRL is indicated to inhibit progression of tumors such as meningioma, breast, colorectal, endometrial and prostate carcinoma [4, 52-57]. Previous studies have demonstrated that B2036, a hGH antagonist, decreased oncogenicity of endometrial carcinoma cells [4] and decreased proliferation of primary human mammary carcinoma cells in vitro [58]. Furthermore, Pegvisomant, the pegylated form of B2036 with FDA approval for the treatment of acromegaly, produced shrinkage of mammary carcinoma xenografts associated with reduced proliferation and increased apoptosis [54]. Similarly, hPRL-G129R is a specific hPRLR antagonist [34]. hPRL-G129R inhibits proliferation by induction of apoptosis in hPRLR positive breast cancer cell lines [34] and prevent early stages of prostate tumorigenesis [57]. Herein, we have therefore used the hGH-G120R mutant to demonstrate that combined inhibition of both autocrine hGH and hPRL decreased oncogenicity of human HCC cell lines. hGH-G120R inhibits hGH binding to either hGH or PRL receptors and also hPRL binding to the hPRL receptor [29]. As previously proposed for mammary and endometrial carcinoma, use of a single dual antagonist to hGH and hPRL may be a preferred approach to inhibit the oncogenic actions of these hormones in HCC as opposed to use of specific antagonists individually.

\section{MATERIALS AND METHODS}

\section{Ethics statement}

Investigations have been conducted in accordance with the ethical standards according to the Declaration of Helsinki and according to national and international guidelines and has been approved by the authors' institutional review board.

\section{Patients and specimens}

Formalin-fixed and paraffin-embedded, HCC and non-neoplastic liver specimens $(n=148)$ were obtained from the Department of Pathology of the First Affiliated Hospital of Anhui Medical University between 2004 and 2007. Fresh HCC and adjacent non-neoplastic liver tissues were immediately mixed with RNAlater and stored at $-80^{\circ} \mathrm{C}$ freezer. The pathological tumor stage was defined according to the tumor-node-metastasis (TNM) classification of the International Union against Cancer ( $6^{\text {th }}$ Edition). The Edmondson grading system was used to define tumor differentiation [59]. Complete follow-up data were obtained on all HCC patients to determine overall survival (OS) and relapse-free survival (RFS). A protocol to use patient samples was approved by the Biomedical Ethics Committee of Anhui Medical University and a written informed consent was obtained from each patient.

\section{Tissue microarray (TMA) Construction, In situ hybridization (ISH) and Immunohistochemistry (IHC)}

TMA constructions and ISH and IHC for hGH and hPRL were performed as previously described [8]. The diameter of each tissue core in the TMA was $1 \mathrm{~mm}$ and three to five representative were obtained from each case and inserted in a grid pattern into a recipient paraffin block. The evaluation of ISH and IHC staining was based on the combined expression pattern of all of the tissue cores from each patient sample. Stained sections were independently assessed for expression of hGH and hPRL with a light microscope by two pathologists without knowledge of the samples associated clinicopathologic information. The sections were scored on the basis of the percentage of cells with staining relative to the background and the staining intensity. Firstly, the extent of staining was scored as $0(0 \%), 1(1 \%-25 \%), 2(26 \%-50 \%), 3(51 \%-75 \%)$, and $4(76 \%-100 \%)$ according to the percentage of the positive staining areas and staining intensity was scored as 0 (negative), 1 (weak), 2 (medium), and 3 (strong). The sum of the extent and intensity score was used as the staining score (0-7) for hGH and hPRL expression. Scores of 0-1, 2-3, 4-5 and 6-7 was designated as,,-+++ and +++ respectively. Scores of - and + was designated as low expression and ++ and +++ was designated as high expression [60].

\section{Cell lines and reagent}

Human cell lines HepG2 (hepatoblastoma cell line) and $\mathrm{HCC}$ cell line PLC/PRF/5 were purchased from ATCC (Rockville, MD, USA). LO2, Bel-7404, QGY-7701, QGY7703 and SMMC-7721 cells were kindly provided by Dr. Lijian Hui (Institute of Biochemistry and Cell Biology, Chinese Academy of Sciences). All cells were maintained in DMEM (Gibco, Grand Island, NY, USA) medium plus 10\% Fetal bovine serum (Hyclone, Beijing, China). STAT3 inhibitor cryptotanshinone was purchased from SigmaAldrich (St Louis, MO, USA).

\section{Constructs, plasmid and siRNA transfection}

The plasmid pcDNA3-hGH was constructed as previously described [4]. The hPRL (Genebank accession number: NM_000948.5) cDNA was subcloned into pcDNA 3 plasmid. pcDNA3-G120R plasmid was generated using a QuickChange Site-Directed Mutagenesis Kit (Stratagene, La Jolla, CA, USA). Bel-7404 and HepG2 stable cell lines (pooled) were established by plasmids 
transfection by Lipofectamine 2000 (Invitrogen, Carlsbad, CA, USA) and then growing cell in G418 $(800 \mu \mathrm{g} / \mathrm{ml}$, SigmaAldrich) containing medium for two weeks. siRNAs targeting hGH (SI03053498 and SI03076311) and hPRL (SI00019019 and SI00019033) were purchased from Qiagen (Hilden, Germany). The four individual siRNAs were mixed equally for transfection by use of HiPerFect transfection reagent (Qiagen).

\section{Semi-quantitative RT-PCR and real-time quantitative PCR}

Total RNA was extracted from cultured cells or fresh tissues with Trizol (Invitrogen). Semi-quantitative RT-PCR and real-time quantitative PCR were performed as previously described [4]. Oligonucleotide sequences are listed in Supplementary Table S6 and S7. Sequences of the other primers used are as described previously [4].

\section{In vitro oncogenicity assays}

Total cell number, BrdU incorporation, measurement of apoptosis (TUNEL assay), soft agar colony formation and three-dimensional Matrigel growth were performed as previously described [4].

\section{Immunoblot}

Immunoblot was performed as previously described [61] by using the following antibodies: hGH (antihGH-2, 1:10000, NIDDK, Bethesda, MD, USA); hPRL (anti-hPRL-IC-5, 1:10000, NIDDK); STAT3 (P30007, 1:1000, Abmart, Shanghai, China); phospho-STAT3 (Y705) (ab76315, 1:10000, Abcam, Cambridge, United Kingdom), Phospho-p44/42 MAPK (Thr202/Tyr204) (9101, 1:1000, Cell Signaling), p44/42 MAPK (4696, 1:1000, Cell Signaling) and GAPDH (M20028, 1:5000, Abmart).

\section{ELISA}

Cells were grown to $90 \%$ confluence in six-well plates. The medium was then changed to serum-free medium for 48h. Quantification of hGH (ab100526, Abcam) and hPRL (DY682, R\&D Systems, Minneapolis, MN, USA) in cell culture conditioned medium and mouse serum hIGF1 (ab100545, Abcam) levels were performed with commercially available ELISA kits as manufactures' instructions.

\section{Immunofluorescence}

Immunostaining of $\mathrm{hGH}$ and $\mathrm{hPRL}$ were performed with a rabbit anti-hGH antibody (anti-hGH-2, 1:150, NIDDK, Bethesda, MD, USA) or rabbit anti-hPRL antibody (anti-hPRL-IC-5, 1:150, NIDDK).

\section{Xenograft}

The mice were maintained in a pathogen-free barrier environment and closely monitored by animal facility staff. All mice work procedures were approved by University of Science and Technology (USTC) Ethics Committee for Animal Care and Use and were performed in accordance with the regulations of animal care of USTC and conformed to the legal mandates and national guidelines for the care and maintenance of laboratory animals. Bel-7404 stable cell lines (Two million) were s.c injected into the right and left flank of BALB/c-nu/nu mice (Slaccas, Shanghai, China). Each group contained six mice. Tumor volume calculation, BrdU and TUNEL immunostaning were performed as previously described [61].

\section{Statistical analysis}

All statistical analyses were performed as previously described [8].

\section{ACKNOWLEDGMENTS}

We thank Dr. Lijian Hui for generously providing LO2, Bel-7404, QGY-7701, QGY-7703 and SMMC-7721 cell lines.

\section{CONFLICTS OF INTEREST}

PEL is an inventor on patent application US20100203060A1. TZ has consulted for and PEL consults for Perseis Therapeutics Ltd. TZ and PEL consult for and have equity interest in Wuhan Long Ke Ltd.

\section{GRANT SUPPORT}

This work was supported by the National Key Scientific Program of China (2012CB934002 and 2010CB912804); the National Natural Science Foundation of China (81302322, 30971492, 30725015, 30873047 and 81572305); Specialized Research Fund for the Doctoral Program of Higher Education (20133402120032 and 20133420120006); the Cancer Science Institute of Singapore through grants from the National Research Foundation and Ministry of Education of Singapore and by a grant from the National Medical Research Council of Singapore [R713-000-163-511]. PEL was also supported by The Chinese Academy of Sciences President's International Fellowship Initiative (PIFI) Grant No. 2015VBA031.

\section{REFERENCES}

1. Harvey S. Extrapituitary growth hormone. Endocrine. 2010;38:335-59.

2. Clevenger CV. Role of prolactin/prolactin receptor signaling in human breast cancer. Breast Dis. 2003;18:75-86. 
3. Fernandez I, Touraine P, Goffin V. Prolactin and Human Tumourogenesis. J Neuroendocrinol. 2010;22:771-7.

4. Pandey V, Perry JK, Mohankumar KM, Kong XJ, Liu SM, Wu ZS, Mitchell MD, Zhu T, Lobie PE. Autocrine human growth hormone stimulates oncogenicity of endometrial carcinoma cells. Endocrinology. 2008;149:3909-19.

5. Perry JK, Emerald BS, Mertani HC, Lobie PE. The oncogenic potential of growth hormone. Growth Hormone \& IGF Research. 2006;16:277-89.

6. Waters MJ, Barclay JL. Does growth hormone drive breast and other cancers? Endocrinology. 2007;148:4533-5.

7. Zhu T, Starling-Emerald B, Zhang X, Lee KO, Gluckman PD, Mertani HC, Lobie PE. Oncogenic transformation of human mammary epithelial cells by autocrine human growth hormone. Cancer Res. 2005;65:317-24.

8. Wu ZS, Yang K, Wan Y, Qian PX, Perry JK, Chiesa J, Mertani HC, Zhu T, Lobie PE. Tumor Expression of Human Growth Hormone and Human Prolactin Predict a Worse Survival Outcome in Patients with Mammary or Endometrial Carcinoma. J Clin Endocrinol Metab. 2011;96:E1619-29.

9. Boutin JM, Jolicoeur C, Okamura H, Gagnon J, Edery M, Shirota M, Banville D, Dusanter-Fourt I, Djiane J, Kelly PA. Cloning and expression of the rat prolactin receptor, a member of the growth hormone/prolactin receptor gene family. Cell. 1988;53:69-77.

10. Husman B, Andersson G, Norstedt G, Gustafsson JA. Characterization and Subcellular Distribution of the Somatogenic Receptor in Rat Liver. Endocrinology. 1985;116:2605-11.

11. Bole-Feysot C, Goffin V, Edery M, Binart N, Kelly PA. Prolactin (PRL) and its receptor: actions, signal transduction pathways and phenotypes observed in PRL receptor knockout mice. Endocr Rev. 1998;19:225-68.

12. Waters MJ, Conway-Campbell BL. The oncogenic potential of autocrine human growth hormone in breast cancer. Proc Natl Acad Sci USA. 2004;101:14992-3.

13. Liu JL, Yakar S, LeRoith D. Conditional knockout of mouse insulin-like growth factor-1 gene using the Cre/loxP system. Proc Soc Exp Biol Med. 2000;223:344-51.

14. Donaghy A, Ross R, Gimson A, Hughes SC, Holly J, Williams R. Growth hormone, insulinlike growth factor-1, and insulinlike growth factor binding proteins 1 and 3 in chronic liver disease. Hepatology. 1995;21:680-8.

15. Snibson KJ, Bhathal PS, Hardy CL, Brandon MR, Adams TE. High, persistent hepatocellular proliferation and apoptosis precede hepatocarcinogenesis in growth hormone transgenic mice. Liver. 1999;19:242-52.

16. Snibson KJ, Bhathal PS, Adams TE. Overexpressed growth hormone $(\mathrm{GH})$ synergistically promotes carcinogen-initiated liver tumour growth by promoting cellular proliferation in emerging hepatocellular neoplasms in female and male GH-transgenic mice. Liver. 2001;21:149-58.

17. Bugni JM, Poole TM, Drinkwater NR. The little mutation suppresses DEN-induced hepatocarcinogenesis in mice and abrogates genetic and hormonal modulation of susceptibility. Carcinogenesis. 2001;22:1853-62.

18. Li S, Hou G, Wang Y, Su X, Xue L. Influence of recombinant human growth hormone (rhGH) on proliferation of hepatocellular carcinoma cells with positive and negative growth hormone receptors in vitro. Tumori. 2010;96:282-8.

19. Lin Y, Li S, Cao P, Cheng L, Quan M, Jiang S. The effects of recombinant human $\mathrm{GH}$ on promoting tumor growth depend on the expression of GH receptor in vivo. $\mathrm{J}$ Endocrinol. 2011;211:249-56.

20. Buckley AR, Putnam CW, Russell DH. Prolactin is a tumor promoter in rat liver. Life Sci. 1985;37:2569-75.

21. Ang S, Wang W, Soe Y, Tan C, Chow W, Kwee AK, Toh H. Identification of three potential biomarkers in early resectable hepatocellular carcinoma. J Clin Oncol. 28:15s, 2010.

22. Costantini S, Capone F, Maio P, Guerriero E, Colonna G, Izzo F, Castello G. Cancer biomarker profiling in patients with chronic hepatitis $\mathrm{C}$ virus, liver cirrhosis and hepatocellular carcinoma. Oncol Rep. 2013;29:2163-8.

23. Wang WW, Ang SF, Kumar R, Heah C, Utama A, Tania NP, Li H, Tan SH, Poo D, Choo SP, Chow WC, Tan CK, Toh HC. Identification of serum monocyte chemoattractant protein-1 and prolactin as potential tumor markers in hepatocellular carcinoma. PLoS ONE. 2013;8:e68904.

24. García-Caballero T, Mertani HM, Lambert A, Gallego R, Fraga M, Pintos E, Forteza J, Chevallier M, Lobie PE, Vonderhaar BK, Beiras A, Morel G. Increased expression of growth hormone and prolactin receptors in hepatocellular carcinomas. Endocrine. 2000;12:265-71.

25. Scheuer A, Grün R, Lehmann FG. Peptide hormones in liver cirrhosis and hepatocellular carcinoma. Oncodev Biol Med. 1981;2:1-10.

26. Yeh YT, Lee KT, Tsai CJ, Chen YJ, Wang SN. Prolactin promotes hepatocellular carcinoma through Janus kinase 2. World J Surg. 2012;36:1128-35.

27. Gao J, Aksoy BA, Dogrusoz U, Dresdner G, Gross B, Sumer SO, Sun Y, Jacobsen A, Sinha R, Larsson E, Cerami E, Sander C, Schultz N. Integrative analysis of complex cancer genomics and clinical profiles using the cBioPortal. Sci Signal. 2013;6:pl1.

28. Cerami E, Gao J, Dogrusoz U, Gross BE, Sumer SO, Aksoy BA, Jacobsen A, Byrne CJ, Heuer ML, Larsson E, Antipin Y, Reva B, Goldberg AP, et al. The cBio cancer genomics portal: an open platform for exploring multidimensional cancer genomics data. Cancer Discov. 2012;2:401-4.

29. Chen WY, Chen NY, Yun J, Wagner TE, Kopchick JJ. In vitro and in vivo studies of antagonistic effects of human growth hormone analogs. J Biol Chem. 1994;269:15892-7.

30. Le Roith D, Bondy C, Yakar S, Liu JL, Butler A. The Somatomedin Hypothesis: 2001. Endocr Rev. 2001;22:53-74.

31. Ram PA, Park SH, Choi HK, Waxman DJ. Growth hormone activation of Stat 1, Stat 3, and Stat 5 in rat liver. 
Differential kinetics of hormone desensitization and growth hormone stimulation of both tyrosine phosphorylation and serine/threonine phosphorylation. J Biol Chem. 1996;271:5929-40.

32. Yang SF, Wang SN, Wu CF, Yeh YT, Chai CY, Chunag SC, Sheen MC, Lee KT. Altered p-STAT3 (tyr705) expression is associated with histological grading and intratumour microvessel density in hepatocellular carcinoma. J Clin Pathol. 2007;60:642-8.

33. Shin DS, Kim HN, Shin KD, Yoon YJ, Kim SJ, Han DC, Kwon BM. Cryptotanshinone inhibits constitutive signal transducer and activator of transcription 3 function through blocking the dimerization in DU145 prostate cancer cells. Cancer Res. 2009;69:193-202.

34. Chen WY, Ramamoorthy P, Chen N, Sticca R, Wagner TE. A human prolactin antagonist, hPRL-G129R, inhibits breast cancer cell proliferation through induction of apoptosis. Clin Cancer Res. 1999;5:3583-93.

35. Levina VV, Nolen B, Su Y, Godwin AK, Fishman D, Liu J, Mor G, Maxwell LG, Herberman RB, Szczepanski MJ, Szajnik ME, Gorelik E, Lokshin AE. Biological significance of prolactin in gynecologic cancers. Cancer Res. 2009;69:5226-33.

36. Stuver SO, Kuper H, Tzonou A, Lagiou P, Spanos E, Hsieh CC, Mantzoros C, Trichopoulos D. Insulin-like growth factor 1 in hepatocellular carcinoma and metastatic liver cancer in men. Int J Cancer. 2000;87:118-21.

37. Park EJ, Lee JH, Yu GY, He G, Ali SR, Holzer RG, Osterreicher $\mathrm{CH}$, Takahashi H, Karin M. Dietary and genetic obesity promote liver inflammation and tumorigenesis by enhancing IL-6 and TNF expression. Cell. 2010;140:197-208.

38. von Horn H, Ekström C, Ellis E, Olivecrona H, Einarsson C, Tally M, Ekström TJ. GH is a regulator of IGF2 promoterspecific transcription in human liver. $\mathrm{J}$ Endocrinol. 2002; 172:457-65.

39. Kaseb AO, Morris JS, Hassan MM, Siddiqui AM, Lin E, Xiao L, Abdalla EK, Vauthey JN, Aloia TA, Krishnan S, Abbruzzese JL. Clinical and prognostic implications of plasma insulin-like growth factor-1 and vascular endothelial growth factor in patients with hepatocellular carcinoma. J Clin Oncol. 2011;29:3892-9.

40. Mazziotti G, Sorvillo F, Morisco F, Carbone A, Rotondi M, Stornaiuolo G, Precone DF, Cioffi M, Gaeta GB, Caporaso N, Carella C. Serum insulin-like growth factor I evaluation as a useful tool for predicting the risk of developing hepatocellular carcinoma in patients with hepatitis C virus-related cirrhosis: a prospective study. Cancer. 2002;95:2539-45.

41. Luo SM, Tan WM, Deng WX, Zhuang SM, Luo JW. Expression of albumin, IGF-1, IGFBP-3 in tumor tissues and adjacent non-tumor tissues of hepatocellular carcinoma patients with cirrhosis. World J Gastroenterol. 2005;11:4272-6.
42. Sohda T, Yun K, Iwata K, Soejima H, Okumura M. Increased expression of insulin-like growth factor 2 in hepatocellular carcinoma is primarily regulated at the transcriptional level. Lab Invest. 1996;75:307-11.

43. Tovar V, Alsinet C, Villanueva A, Hoshida Y, Chiang DY, Solé M, Thung S, Moyano S, Toffanin S, Mínguez B, Cabellos L, Peix J, Schwartz M, et al. IGF activation in a molecular subclass of hepatocellular carcinoma and pre-clinical efficacy of IGF-1R blockage. J Hepatol. 2010;52:550-9.

44. Höpfner M, Huether A, Sutter AP, Baradari V, Schuppan D, Scherübl H. Blockade of IGF-1 receptor tyrosine kinase has antineoplastic effects in hepatocellular carcinoma cells. Biochem Pharmacol. 2006;71:1435-48.

45. Kaulsay KK, Mertani HC, Törnell J, Morel G, Lee KO, Lobie PE. Autocrine stimulation of human mammary carcinoma cell proliferation by human growth hormone. Exp Cell Res. 1999;250:35-50.

46. Tang JZ, Kong XJ, Banerjee A, Muniraj N, Pandey V, Steiner M, Perry JK, Zhu T, Liu DX, Lobie PE. STAT3alpha is oncogenic for endometrial carcinoma cells and mediates the oncogenic effects of autocrine human growth hormone. Endocrinology. 2010;151:4133-45.

47. Wu WY, Li J, Wu ZS, Zhang CL, Meng X-L. STAT3 activation in monocytes accelerates liver cancer progression. BMC Cancer. 2011;11:506.

48. He G, Karin M. NF- $\kappa$ B and STAT3 - key players in liver inflammation and cancer. Cell Res. 2011;21:159-68.

49. Alzhanov D, Mukherjee A, Rotwein P. Identifying growth hormone-regulated enhancers in the Igf1 locus. Physiol Genomics. 2015; 47:559-68.

50. Varco-Merth B, Rotwein P. Differential effects of STAT proteins on growth hormone-mediated IGF-I gene expression. Am J Physiol Endocrinol Metab. 2014;307:E847-55.

51. Hartwell HJ, Petrosky KY, Fox JG, Horseman ND, Rogers AB. Prolactin prevents hepatocellular carcinoma by restricting innate immune activation of c-Myc in mice. Proc Natl Acad Sci USA. 2014;111:11455-60.

52. Bougen NM, Steiner M, Pertziger M, Banerjee A, BrunetDunand SE, Zhu T, Lobie PE, Perry JK. Autocrine human GH promotes radioresistance in mammary and endometrial carcinoma cells. Endocr Relat Cancer. 2012;19:625-44.

53. Dagnaes-Hansen F, Duan H, Rasmussen LM, Friend KE, Flyvbjerg A. Growth hormone receptor antagonist administration inhibits growth of human colorectal carcinoma in nude mice. Anticancer Res. 2004;24:3735-42.

54. Divisova J, Kuiatse I, Lazard Z, Weiss H, Vreeland F, Hadsell DL, Schiff R, Osborne CK, Lee AV. The growth hormone receptor antagonist pegvisomant blocks both mammary gland development and MCF-7 breast cancer xenograft growth. Breast Cancer Res Treat. 2006;98:315-27. 
55. Hou L, Xu B, Mohankumar KM, Goffin V, Perry JK, Lobie PE, Liu DX. The prolactin receptor mediates HOXA1stimulated oncogenicity in mammary carcinoma cells. Int J Oncol. 2012;41:2285-95.

56. McCutcheon IE, Flyvbjerg A, Hill H, Li J, Bennett WF, Scarlett JA, Friend KE. Antitumor activity of the growth hormone receptor antagonist pegvisomant against human meningiomas in nude mice. J Neurosurg. 2001;94:487-92.

57. Rouet V, Bogorad RL, Kayser C, Kessal K, Genestie C, Bardier A, Grattan DR, Kelder B, Kopchick JJ, Kelly PA, Goffin V. Local prolactin is a target to prevent expansion of basal/stem cells in prostate tumors. Proc Natl Acad Sci USA. 2010;107:15199-204.

58. Chiesa J, Ferrer C, Arnould C, Vouyovitch CM, Diaz JJ, Gonzalez S, Mares P, Morel G, Wu ZS, Zhu T, Lobie PE, Mertani HC. Autocrine proliferative effects of hGH are maintained in primary cultures of human mammary carcinoma cells. J Clin Endocrinol Metab. 2011;96:E1418-26.

59. Edmondson HA, Steiner PE. Primary carcinoma of the liver: a study of 100 cases among 48,900 necropsies. Cancer. 1954;7:462-503.

60. Park SI, Zhang J, Phillips KA, Araujo JC, Najjar AM, Volgin AY, Gelovani JG, Kim SJ, Wang Z, Gallick GE. Targeting SRC family kinases inhibits growth and lymph node metastases of prostate cancer in an orthotopic nude mouse model. Cancer Res. 2008;68:3323-33.

61. Kong X, Li G, Yuan Y, He Y, Wu X, Zhang W, Wu Z, Chen T, Wu W, Lobie PE, Zhu T. MicroRNA-7 inhibits epithelial-to-mesenchymal transition and metastasis of breast cancer cells via targeting FAK expression. PLoS ONE. 2012;7:e41523. 